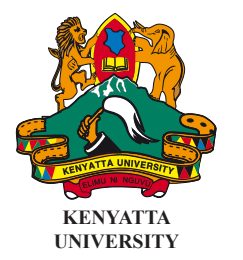

ISSN 1563-1028
CHEMCHEMI

International Journal of Humanities and Social Sciences

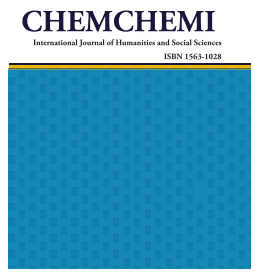

Volume 10 Number 2, 2016

\title{
THE INFLUENCE OF CULTURE IN THE INTERPRETATION OF JAPANESE LANGUAGE INSTRUCTIONAL MATERIALS
}

\author{
Wamuti, L., Bwire, A.M. and Ndethiu, S.
}

\begin{abstract}
The mastery of any foreign language is affected by several factors, among them the cultural environment in which the language learning takes place. In an attempt to reinforce the language learning process, instructors of foreign language often make use of language instructional materials to enable students engage in motivating, appealing and interactive learning activities. The content of such instructional materials must be interpreted easily and accurately if they are to be effective. A major impediment in interpretation of instructional materials is the socio-cultural barrier which may interfere with the learner's ability to decode the intended meaning in the content of the instructional materials. This hinders the achievement of the language lesson objectives. This paper discusses the influence of cultural elements on interpretation of the information in Japanese Language Instructional Materials (JLIM) by Kenyan students. This paper is based on the results of a pilot study carried out among college Japanese students in Kenya. It attempts to establish the influence and impact of culture on the interpretation of the Japanese language instructional materials by the Kenyan students. It is part of an ongoing research aimed at identifying the factors influencing the mastery of the Japanese language among Kenyan students. The research is guided by schema theory, which describes the process by which readers refer to their own background knowledge in order to comprehend new information. The learners of Japanese language were subjected to some instructional materials and asked to answer several questions designed to establish their interpretation of the materials. Their responses were compared with what is expected from the Japanese cultural context. Data was collected through a questionnaire. The results of the study show that unfamiliar cultural elements in the instructional materials negatively influence the interpretation of information. It is therefore recommended that the design of language instructional materials should take into consideration the culture of the learners.
\end{abstract}

Keywords: Japanese language instructional materials, mastery of language, socio-cultural effects, interpretation, Schema theory, cultural schema.

\section{Introduction}

Japanese language is spoken mainly by the people of Japan as their native language. The language is gradually gaining popularity in Kenya and in Africa. Kenya is one of the leading centres for the development of Japanese-language education in sub-Saharan Africa with approximately 1,000 students studying the language either as a foreign or a second foreign language for those who have already acquired some proficiency in some other foreign languages such as French, Italian, German and Chinese. The 
language is taught in some universities and in many middle level colleges, mainly to serve in the tourism and hospitality industry. The main institutions currently offering the language are those dealing with tourism and hospitality courses such as the Kenya Utalii College (KUC), Kenya Wildlife Services Training Institute (KWSTI), United States International University - Africa (USIU) and Kenyatta University $(\mathrm{KU})$, among others. The distribution of students studying the language in Kenya is shown in Table 1.

Table 1: Number of students studying Japanese in Kenya

\begin{tabular}{|l|l|r|r|r|r|}
\hline \multirow{2}{*}{ S/no. } & \multirow{2}{*}{ Institution } & \multicolumn{2}{|c|}{ Japanese Proficiency Level } & \multirow{2}{*}{ Total } \\
\cline { 2 - 5 } & Basic & Intermediate & Advanced & \\
\hline 1 & Kenyatta University (KU) & 85 & 5 & 0 & 90 \\
\hline 2 & Kenya Utalii College (KUC) & 210 & 0 & 0 & 210 \\
\hline 3 & $\begin{array}{l}\text { United States International } \\
\text { University (USIU) }\end{array}$ & 85 & 15 & 0 & 100 \\
\hline 4 & $\begin{array}{l}\text { Strathmore University } \\
\text { Kenya Wildlife Training } \\
\text { Institute }\end{array}$ & 200 & 0 & 0 & 200 \\
\hline 6 & $\begin{array}{l}\text { Catholic University of Eastern } \\
\text { Africa (CUEA) }\end{array}$ & 50 & 0 & 0 & 200 \\
\hline 7 & Others & 187 & 0 & 0 & 50 \\
\hline
\end{tabular}

Source: Fieldwork (September 2014)

Just like for all other languages, there are challenges inherent in the teaching and learning of Japanese language. One of the challenges is the interference with the learner's first language, which is an inevitable aspect in foreign language learning (McLaughlin, 2012). Such interference is especially evident when the structure and systems for the first and target languages are different. It has been reported by many authors that first language interference in learning a second language is greatest when the languages involved are distinct in structure and system. Japanese and English are two languages which are very different in many aspects. Kenyan students tend to use their knowledge and experience of English language to interpret and to learn the Japanese language. Thus, their knowledge and experience of the English language influences the way they learn and use the Japanese language. Some of the sentences which they construct are a clear indication of a situation where one is thinking in English while speaking in Japanese language. For example, a student will translate a Japanese statement watashi wa ie ni ikimasu (I am going home) to say I home going, which is a direct translation from Japanese to English. Tang (1999) argues that to speak a language well, one has to be able to think in that language. The difference in the sentence structures for the first and target languages also slows down the learning process since the students tend to base their learning of Japanese language on their knowledge of English language. For example, Japanese language has a Subject-Object-Verb word order, such that the subject comes first; the verb last, and if the verb takes an object, it comes in the middle. English and Kiswahili languages, on the other hand, are Subject-VerbObject languages. Therefore, mistakes in the construction of a correct Japanese language sentence are very common.

Some of the difficulties that Kenyan learners have with Japanese Language are not due to problems with the language itself but are more as the result of cultural differences. Failure to understand the cultural meaning of the context within which a word, a phrase, a sentence, a drawing, or even a picture occurs sometimes results in misinterpretation of the message. For example, the Japanese greet each other by bowing down their heads and not by shaking their hands. On the other hand, in Kenya, greeting styles vary from one community to another. For example, the Maasai elderly men greet ladies by placing hands 
on their head. The Kikuyu greetings are elaborate, whereby age-mates greet by grasping the palm and the thumb alternately for a number of times as they exchange pleasantries. If Kenyan students are presented with a picture of people bowing down, they are not likely to interpret the action to be greetings for they do not relate such a schema with greetings. In such a situation where the students do not have the cultural meanings, they may attach the wrong meanings to the symbols of communication.

The influence of culture on effectiveness of language learning is supported by Byram (1994), who argues that the language rooted in the context can be thoroughly comprehensible only when the cultural context is understood. The complexity of understanding a language in terms of its culture is also mentioned by Fries (1963) who states that when reading a foreign language text, we find three levels of meaning: lexical meaning, grammatical meaning, and socio-cultural meaning. The lexical and structural meanings can be looked up in a dictionary by the students, but the socio cultural meanings are difficult for the foreign or second language learners to penetrate as it implies the values, beliefs and attitudes of the speakers of the target language. Understanding a language in terms of its culture is complex with many different characteristics. Therefore, language students and language instructors should understand which variant language forms are appropriate within which context in order to do an accurate interpretation. However, in order to empower the instructors, several seminars and conferences on effective teaching of the language have been organized at the Japanese Culture \& Information Centre (JCIC) in Kenya, where Japanese Language teaching experts are invited as resource persons. For example, in August, 2014 an international conference on teaching Japanese to beginners was held in Nairobi. Such conferences are very useful as far as teaching methods and theories are concerned but the socio-cultural gap remains un-bridged. In an attempt to bridge this gap, the language instructors are offered training in Japan every 5 years by the Japan Foundations where they interact with language, the culture and the people.

Most of the Japanese language students in Kenya hardly use Japanese language outside the classroom. Therefore, the retention rate of the language is quite low, making it difficult for the students to achieve adequate communicative and linguistic competencies. Krashen and Terrell (1992) argue that the purpose of language instruction is to allow the learner to understand language outside the classroom, so that ultimately he or she can utilize it in the real world, as well as in the classroom for progress. Thorndike (1999) states that for maximum learning, the principle of frequency should be applied in instructions. This principle states that those things most often repeated are best remembered and that human mind can rarely retain, evaluate, and apply new concepts or practices after only a single exposure.

The number of students taking Japanese language at advanced levels in Kenya has been very low, compared to those who take the language at the basic level. Some students learn Japanese language out of personal interest, meaning that the language is not a course requirement for the main course they are taking in their respective colleges. Such students are intrinsically motivated and easy to instruct. However, some students learn the language because the course they are majoring in requires a foreign language. Such students are excited about the Japanese language during the initial stages but as the learning progresses, the content becomes more demanding and the interest goes down.

Besides the class activities, the students studying Japanese are encouraged to engage in cultural activities which promote and enrich their understanding of the language. These include enrolling and participating in Japanese language clubs where they engage in various cultural activities such as karate, karaoke, origami, cultural dances, drama and watching Japanese movies. In addition, JCIC organizes cultural activities 
where Japanese language students participate. One such activity that has a major impact in Japanese learning is the annual national speech contest, where learners and instructors participate, and prizes awarded to the best performers. During these events, the participants are also introduced to other cultural aspects including sampling of Japanese cuisine and trying out Japanese traditional attire.

Participation in annual Japanese language examination is another activity which promotes language learning. Ambitious students who wish to advance in the language often register for international Japanese Language Proficiency Test (JLPT), which is offered at five different levels, the highest being level N1 and the lowest level N5. However, many students drop out at level N5. For example in 2013, out of the 88 Japanese Language candidates, 70 of them were for level N5, representing 79.5\%, while only 2 were registered for level N1, representing a mere 2.2\% (Japan Educational Exchange Services, 2013). Motivating the entire group of students and sustaining that motivation throughout the course is therefore a major challenge the instructors have to deal with. The distribution of participation for all levels is summarized in Table 2. It can be seen in this table that there is a sharp decrease of numbers as the proficiency levels rises.

Table 2: Participation in JLPT in 2013

\begin{tabular}{|l|c|c|c|c|c|c|}
\hline $\begin{array}{l}\text { Proficiency Level (Level } \\
\text { N1 is the highest and N5 } \\
\text { lowest) }\end{array}$ & N5 & N4 & N3 & N2 & N1 & Total \\
\hline No. of participants & 70 & 6 & 7 & 3 & 2 & $\mathbf{8 8}$ \\
\hline Percentage & 79.55 & 6.82 & 7.95 & 3.41 & 2.27 & $\mathbf{1 0 0}$ \\
\hline
\end{tabular}

\section{Literature Review}

\section{Role of Instructional Materials in Language Teaching}

Instructional materials play a major role in motivating the learner. It is therefore important to identify suitable instructional materials for the instructor to effectively deliver the language content. It has been reported in literature that cultural mismatch between the learners' culture and the culture in the instructional resources can interfere with the learners' decoding of the messages, resulting to non achievement of the instructional goals (Samovar, et al., 1981; Norrizan, 1993); Kramsch, 1987; and Moore, 1991). Steffensen et al. (1979) also note that when students are familiar with cultural norms, they make a better interpretation of the text than when they are not. Further, Alptekin (2006) reported positive effects in reading comprehension where the content is culturally familiar. Therefore, learners of a given language make use of their home cultural schemata in relating new information to what they already know and consequently, interpret the intended meaning for given instructional materials. When some key concepts are absent in their cultural schemata, they may misinterpret the information. Schemas are knowledge structures that influence individuals' expectations and interpretations. They are based on past experience settled as a means of accommodating new information, and hence making sense of them. An existing schema facilitates learning enabling fast integration of new associations, even when learning opportunities are relatively limited in number (Tse et al., 2007). Further, Carrell (1987) argues that information with familiar rhetorical organization is easier to comprehend than that with unfamiliar rhetorical organization. In addition, from the viewpoint of Hudson (1982), comprehension of a message entails drawing information from both the message and the internal schemata until sets are reconciled as a single schema or message.

For the Japanese language students in Kenya, sometimes the information in the instructional materials 
does not relate to what exists in their culture, making it difficult to decode. In some cases, the information in the instructional material is deeply rooted on the Japanese culture, resulting to misunderstanding and misinterpretation of the information and consequently to decline in the interest in studying the language.

Maley (1986) states that when a teacher introduces language teaching materials, such as books or handouts, they must understand that these will be viewed differently by students depending on their cultural views. People from different cultures are likely to have different views and interpretations of instructional materials designed within a different cultural context. The design of language instructional materials must therefore take into consideration the socio-cultural background of the intended users if they are to be of value to learners. The mastery of any foreign language is influenced by among other factors, the culture of the learner and that of the target language (Byram, 1994).

Japanese language instructional materials (JLIM) are produced in Japan by experts for the purpose of teaching the language to non-Japanese all over the world. These materials are intended to meet the needs of the learners of Japanese language, to acquire both linguistic and cultural competence in the language. However, the learners may have difficulties in the interpretation of the concepts in the language instructional materials as a result of socio-cultural differences. It is not clear however, to what extent cultural elements contained in the Japanese language instructional materials are misinterpreted, and the effect of misinterpretation in the mastery of the Language. This study therefore sought to determine the influence of culture in the interpretation of instructional materials.

\section{Theoretical and Conceptual Frameworks}

Studies have shown that there is no significant difference between the way the first language and subsequent languages are acquired or learned. For example, Van Pattern, (2003), in the Processing Instruction Theory, argues that the basic principles of language mastery, whether they are for $\mathrm{L}_{1}, \mathrm{~L}_{2}$ or foreign-language mastery, share many similarities. Similar findings have been reported by Schmidt and Lee, (2005), in the language processing hypothesis and Ellis (2005) in the associative learning theory. Other theories relating to second language and foreign language learning and acquisition include Krashen's monitor model theory (Krashen, 1985), Vygotsky's socio-cultural theory of human mental processing (Vygotsky, 1962): Swain's theory (Swain et al., 1990), and the schema theory (Anderson and Pearson, 1977).

This study adopted the schema theory, which describes the process by which individuals refer to their own background knowledge in order to comprehend new information. The theory is based on the belief that every act of comprehension involves one's knowledge of the world and that accurate decoding of information depends on how much related schema the decoder possess while decoding the information. Tse et al. (2007) note that an existing schema facilitates learning enabling fast integration of new associations, even when learning opportunities are relatively limited in number. Further, from the viewpoint of Hudson (1982), comprehension of a message entails drawing information from both the message and the internal schemata until sets are reconciled as a single schema or message. Failure to understand a text may be caused by lack of appropriate schemata that can easily fit with the content of the text. Therefore, where learners have had different life experiences with the writer, the writer's intention may differ from the learners' comprehension and interpretation of information. In this study, we postulate that the designers of the JLIM are influenced by their language and that encoding and decoding of the information in the instructional material may differ due to cultural differences. 
The conceptual framework relating the instructional materials to their interpretation is shown in Figure 1. The instructional materials generally carry with them the culture of the designers of the materials while the interpretation of the information in these materials is dependent on the learners understanding of the target language culture.

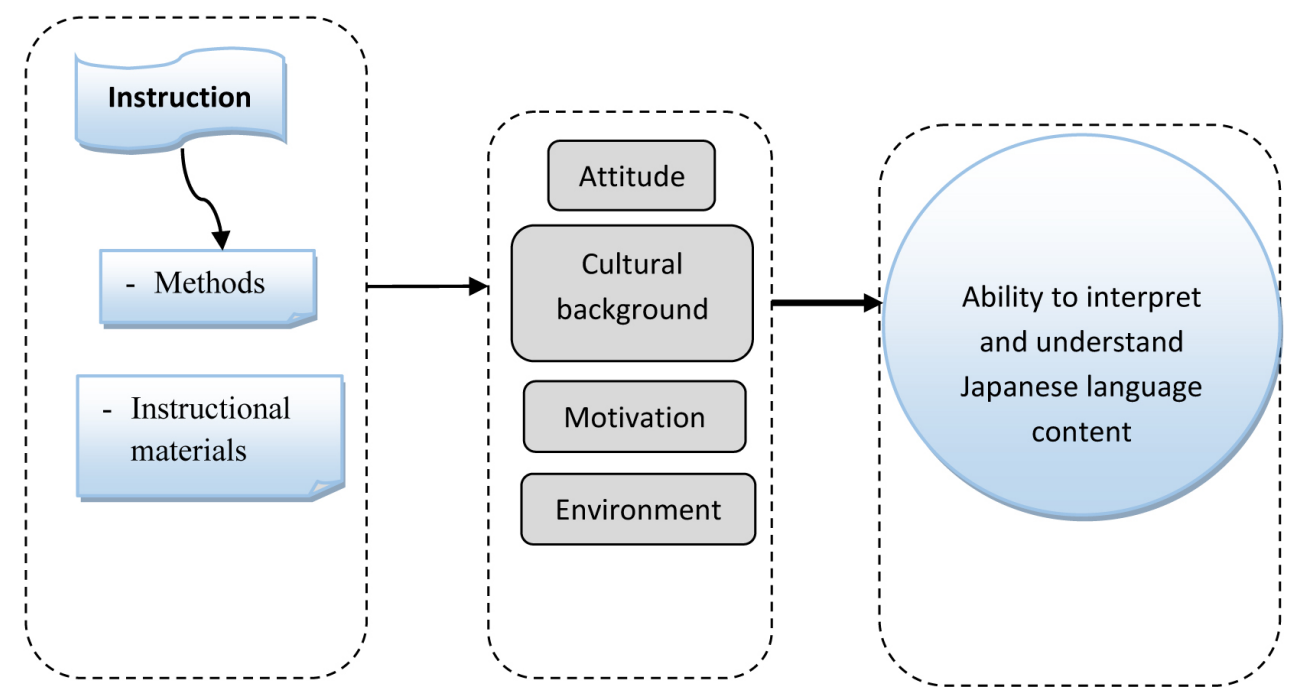

Figure 1 Conceptual framework

The cultural differences may also influence the attitude of the learners which may in turn affect the accuracy of interpretation and consequently the mastery of the language. The ability to interpret may also be influenced by the level of intelligence of the learner as well as environment, among other factors. In this case, the instructional materials and the instructional methods are the independent variables while the ability to interpret is the dependent variable. The learner's attitude, intelligence, cultural background and environment are some of the intervening variables.

\section{Data Collection}

This study was carried out at Kenya Utalii College (KUC) which is a public institution focusing on training for tourism and hospitality industry. KUC has over 200 students studying Japanese language. Since the language curriculum offered at KUC is geared towards a particular purpose; it is not generic and the language instruction focuses mainly on applications. The language taught is thus more communicative than linguistic. Typical Japanese language instructional materials employed to enhance the learning activities by instructors in Kenya include flashcards, which are imported from Japan. The cards generally bear no instructions on how to use and the instructor has to decide the use depending on the content and the intended outcome. 
Table 3: Details of flashcards used

\begin{tabular}{|c|c|c|c|}
\hline $\begin{array}{c}\text { Card } \\
\text { No. }\end{array}$ & Description & Content to be taught & $\begin{array}{c}\text { Culturally unfamiliar } \\
\text { element(s) }\end{array}$ \\
\hline 1. & $\begin{array}{l}\text { A man borrowing money from } \\
\text { colleague }\end{array}$ & The verb borrow & $\begin{array}{l}\text { Scratching of head when } \\
\text { seeking favour }\end{array}$ \\
\hline 2. & $\begin{array}{l}\text { A picture of a man wearing } \\
\text { shoes, using a shoe horn }\end{array}$ & $\begin{array}{l}\text { The verb putting on } \\
\text { shoes }\end{array}$ & Use of shoe horn \\
\hline 3. & $\begin{array}{l}\text { A man leaving the office ahead } \\
\text { of his colleagues after work }\end{array}$ & $\begin{array}{l}\text { Excusing oneself to } \\
\text { leave ahead of others } \\
\text { in work place }\end{array}$ & $\begin{array}{l}\text { Bowing at the door, } \\
\text { facing colleagues }\end{array}$ \\
\hline 4 & $\begin{array}{l}\text { Picture showing traditional } \\
\text { Japanese drama }\end{array}$ & $\begin{array}{c}\text { Japanese traditional } \\
\text { drama }\end{array}$ & The drama setup \\
\hline 5 & $\begin{array}{l}\text { A mother bidding children } \\
\text { goodnight }\end{array}$ & The verb goodnight & $\begin{array}{c}\text { Children bowing beside } \\
\text { the bed }\end{array}$ \\
\hline 6. & $\begin{array}{l}\text { Pictures depicting the four } \\
\text { seasons of the year }\end{array}$ & $\begin{array}{l}\text { Names of the four } \\
\text { seasons in Japan }\end{array}$ & None \\
\hline 7. & $\begin{array}{l}\text { Picture depicting like and } \\
\text { dislike of various foods and } \\
\text { other items }\end{array}$ & $\begin{array}{l}\text { Japanese words for } \\
\text { like and dislike }\end{array}$ & None \\
\hline 8. & $\begin{array}{l}\text { A picture depicting some } \\
\text { important occasions in life }\end{array}$ & $\begin{array}{l}\text { Japanese word for } \\
\text { congratulations }\end{array}$ & New year celebrations \\
\hline 9. & $\begin{array}{l}\text { A boy wondering if to go for a } \\
\text { picnic, considering the weather }\end{array}$ & $\begin{array}{l}\text { Japanese phrase for if } \\
\text { (a)happens I will do } \\
\text { (b) }\end{array}$ & None \\
\hline 10 & $\begin{array}{l}\text { A man asking for direction from } \\
\text { a policeman }\end{array}$ & $\begin{array}{l}\text { How to ask for } \\
\text { directions }\end{array}$ & None \\
\hline 11. & $\begin{array}{l}\text { A man leaving home and telling } \\
\text { wife he will be late }\end{array}$ & $\begin{array}{c}\text { Stating what } \\
\text { someone else is } \\
\text { saying (direct speech) }\end{array}$ & $\begin{array}{c}\text { Manner of dressing for } \\
\text { the wife }\end{array}$ \\
\hline 12 & $\begin{array}{l}\text { A man who has forgotten some } \\
\text { information }\end{array}$ & The verb forget & None \\
\hline
\end{tabular}

In this study, the instructional materials used were flashcards that are usually employed in teaching of nouns, verbs, adjectives and other word classes. Some 12 cards were randomly selected from a set of 200 cards used to teach the syllabus. These cards were numbered for ease of identification and then examined for any culturally unfamiliar elements, and out of these, five (5) were seen to have no culturally unfamiliar elements while the rest (7) were found to have some elements that were culturally unfamiliar to the Kenyan students. Details of these flashcards are given in Table 3. Figure 2 shows a sample of the flashcards used in this study.
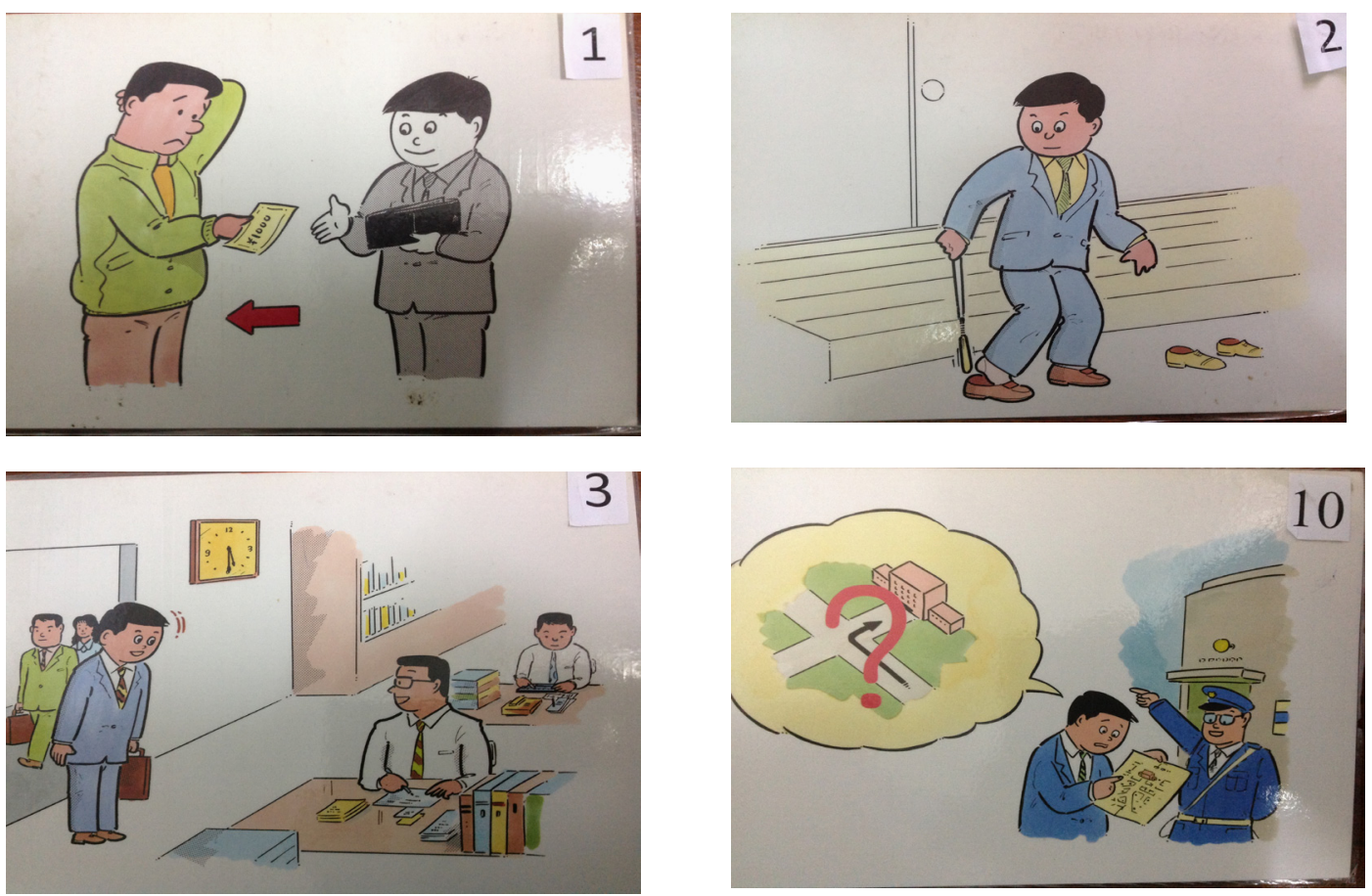

Figure 2: A sample of the flashcards used in study 
Table 4: Results on Interpretation of Instructional Materials

\begin{tabular}{|l|c|c|c|}
\hline $\begin{array}{c}\text { Card } \\
\text { No. }\end{array}$ & $\begin{array}{c}\text { Any culturally } \\
\text { unfamiliar element? }\end{array}$ & $\begin{array}{c}\text { No. correctly } \\
\text { interpreted }\end{array}$ & $\begin{array}{c}\text { No. } \\
\text { misinterpreted }\end{array}$ \\
\hline 1. & Yes & 1 & 14 \\
\hline 2. & Yes & 4 & 11 \\
\hline 3. & Yes & 0 & 15 \\
\hline 4. & Yes & 4 & 11 \\
\hline 5. & Yes & 7 & 8 \\
\hline 6. & No & 11 & 4 \\
\hline 7. & No & 7 & 8 \\
\hline 8. & Yes & 4 & 11 \\
\hline 9. & No & 8 & 7 \\
\hline 10. & No & 15 & 0 \\
\hline 11. & Yes & 2 & 13 \\
\hline 12. & No & 6 & 9 \\
\hline
\end{tabular}

A total of 30 students were randomly selected as the respondents to describe and interpret the information in each of the cards. These students were divided into two groups of 15 each. The members of the first group were asked to interpret individually, the information for cards no. 1-6 while those in the second group interpreted cards no. 7-12. The information obtained from the respondents was then analysed to determine the influence of cultural difference in the interpretation of the information.

\section{Results and Discussion}

The results on interpretation of the flashcards presented to the students are given in Table 4. In this table, the number of respondents that correctly interpreted and those that misinterpreted for each of the flashcards is presented. It is seen that for cards no. 6, 9 and 10, which have no culturally unfamiliar elements, the information was interpreted correctly by more students. However for cards no. 7, and 12, more respondents misinterpreted the information despite the fact that there were no apparent elements which were culturally unfamiliar. For card no. 7, which depicted likes and dislikes, the information for dislike of food can be interpreted to mean that the person is full, or has already eaten. For card no. 12, which also has no culturally unfamiliar elements, the misinterpretation could be as a result of several different possible interpretations, including sickness and insanity, among others.

It can also be seen that for all those cards with culturally unfamiliar elements, the number of students who misinterpreted is much higher than those who interpreted correctly. In order to give a clear view of the effect of culturally unfamiliar elements, we separate those with culturally unfamiliar elements from those without and present the above results in graphical form in Figures 3 and 4. 


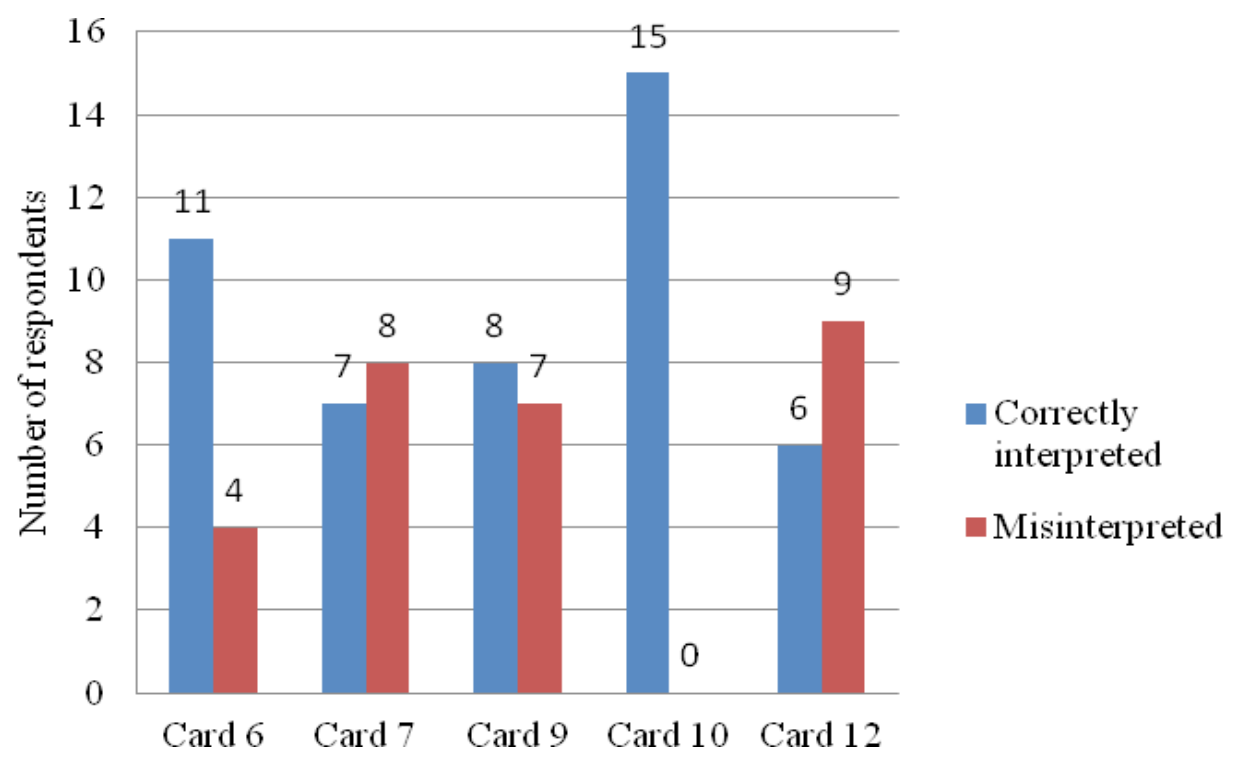

Figure 3: Results on interpretation of flashcards with culturally familiar items

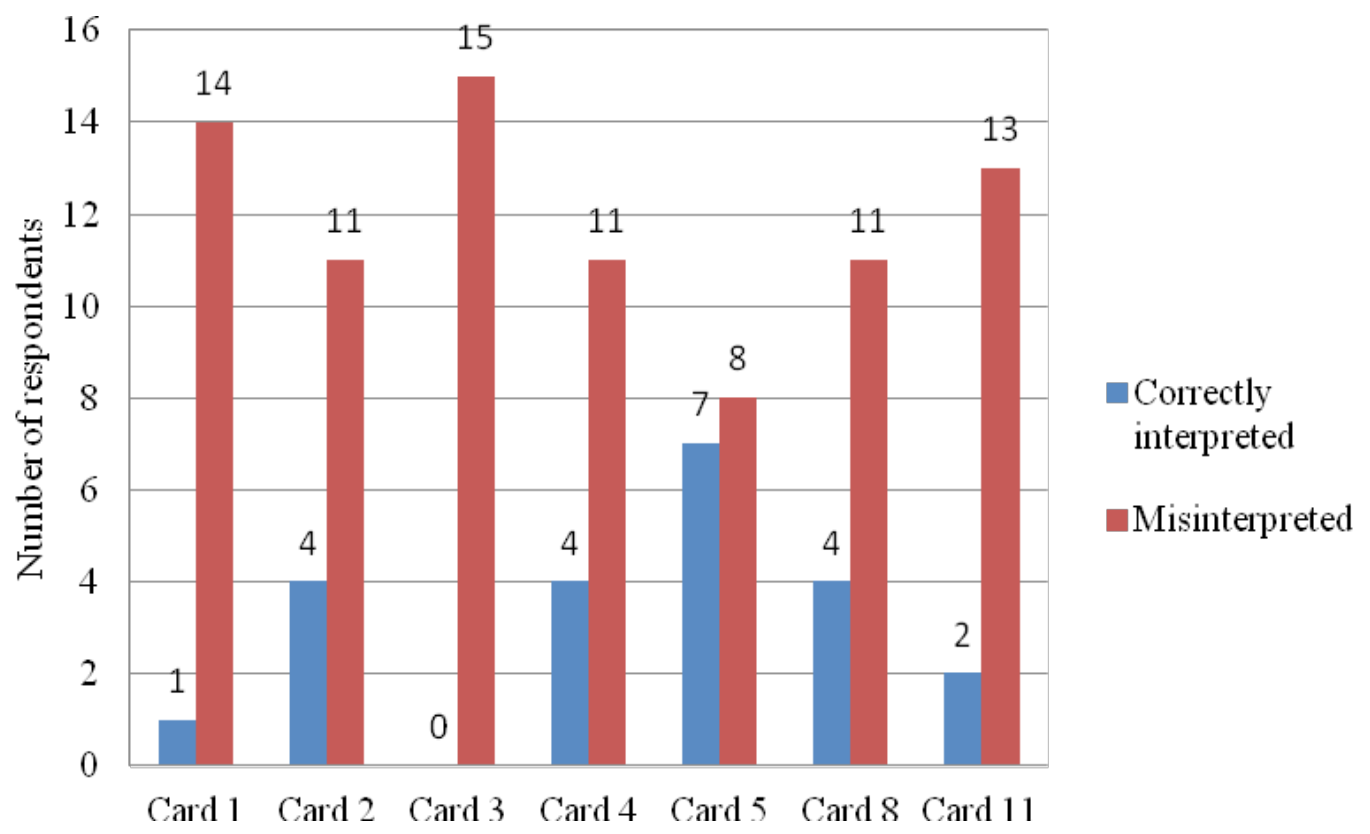

Figure 4: Results on interpretation of flashcards with culturally unfamiliar items

Considering all the cards with culturally unfamiliar elements, that is, cards no. 1, 2, 3, 4, 5, 8, and 11, it is seen that there were only a total of 22 cases of correct interpretation out of 105 possible cases, which is $20.95 \%$. On the other hand for the cards with no culturally unfamiliar elements, that is, cards no. 6 , $7,9,10$ and 12, there were 47 cases of correct interpretation out of 75 possible cases, which represents $62.7 \%$. It is therefore clear that the use of culturally unfamiliar elements in teaching and learning materials in Japanese negatively influence the interpretation of information. This may have a negative effect in the mastery of the language. It is also clear that when foreign language learners are exposed to familiar material, they are more likely to comprehend the information.

It is therefore necessary that language instructional materials designers take into consideration the culture of the learners in the design in order to enhance the learning process. Colleges teaching Japanese as a foreign language (JFL) need to take cognisance of the underlying factors in low acquisition by Kenyan students of JFL and design instructional materials that are culturally relevant. Foundational or introductory topics in the curriculum could emphasise more on the Kenyan learners' understanding of the Japanese 
culture. It is also important that the JFL curriculum used in colleges is reviewed with the above in mind. There is need for synergy building between the JCIC and colleges/universities offering JFL to strengthen capacity building of teachers of Japanese in Kenya in the light of localising approaches and resources in the teaching of the language.

\section{Conclusion}

This paper has analyzed the influence of culturally unfamiliar elements in interpretation of information in Japanese Language Instructional Materials. It was found that culturally unfamiliar elements negatively influence the interpretation of information in the instructional materials. It is therefore recommended that the culture of the learners should be taken into consideration in the design of the language instructional materials in order to enhance the learning process.

\section{References}

Alptekin, C. (2006). Cultural familiarity in inferential and literal comprehension in L2 reading. System, 34(4), 494-508.

Anderson, R.C. \& Pearson, P.D. (1977). A Schema-Theoretic View of Basic Processes in Reading Comprehension, Cambridge: CUP, 1984.

Byram, M. (1994). Teaching and Learning Language and Culture. Bridgend: WBC Ltd.

Fries, C. (1963). Linguistics and Reading. New York: Holt, Rinehart \& Winston.

Hudson, T. (1982). The effects of induced schemata on the 'Short Circuit' in L2 reading performance. Language learning, 32, 1-33.

Carrell, P.L. (1987). Readability in ESL. Reading in a Foreign Language. Reading in a foreign language, 4(1), 21-40.

Ellis, N. (2005). Language acquisition as rational contingency learning. Applied Linguistics, 27(1), 1-24.

Hudson, T. (1982). The effects of induced schemata on the 'Short Circuit' in L2 reading performance. Language learning, 32, 1-33.

Kramsch, C. (1987). Socialization and literacy in a foreign language: Learning through interaction. Theory into Practice, 26(4), 243-250.

Krashen, S. (1985). The input hypothesis: Issues and implications, New York: Longman

Krashen, S., \& Terrell, T. (1992). The natural approach language acquisition in the classroom. Oxford: Pergamon

Maley, A. (1986). A miracle of rare device: the teaching of English in China. In Valdes, J. M. (Ed.) Culture bound: bridging the cultural gap in language teaching. Cambridge: Cambridge University Press.

McLaughlin, B. (2012). Second Language Acquisition in Childhood: Volume 2, Psychology Press, Taylor $\&$ Francis.

Moore, J. (1991). An analysis of the cultural content of post-secondary textbooks for Spanish: Evidence of information processing strategies and types of learning in reading selections and post-reading adjunct questions. Doctoral dissertation, University of Minnesota, Minneapolis.

Norrizan, R. (1993). Cultural Considerations in ESL Texts; A sociolinguistic approach at facilitating ESL learning in towards more effective learning and teaching of English, Proc. $2^{\text {nd }}$ Int. Conf. Malaysian English Language Teaching Association. Selangor: Malaysia.

Samovar, L. Porter. R. \& Jain, N. (1981). Understanding Intercultural Communication, Belmont, CA: Wadsworth.

Schmidt, R., \& Lee, T. L. (2005). Motor control and learning: A behavioral emphasis. Champaign, IL: 
Human Kinetics.

Stacey, M. (1969). Methods in social research. Pergamon Press, Oxford.

Swain, M., Harley, B. \& Cummins, P. (1990). The Development of Second language proficiency. New York: Cambridge University Press.

Steffensen, M. S., Joag-Dev, C., \& Anderson, R. (1979). A cross-cultural perspective on reading comprehension. Reading Research Quarterly, 15, 10-29.

Tang, R. (1999). The Place of "Culture" in the foreign language classroom: A reflection. The Internet TESL Journal, 5(8).

Thorndike, E. (1999). Education Psychology. New York: Routledge.

Tse, D., Langston, R. F., Kakeyama, M., Bethus, I., \& Spooner, P. A. (2007). Schemas and memory consolidation, Science, 316, 76-82.

VanPattern, B. (2003). From input to output. Boston, MA: McGraw-Hill.

Vygotsky, L. (1962). Thought and language. Cambridge, MA: MIT Press.

\section{About the Authors}

Dr. Wamuti is faculty Department of Foreign Languages while Dr. Bwire and Dr. Ndethiu are faculty Department of Communication Technology, Kenyatta University. 